\title{
Comparison of Conventional and Variable Frequency Microwave Curing of SU8 Photoresist: Effects on the Dielectric, Thermal, and Morphological Properties
}

\author{
Piyachat Wattanachai $^{1, \mathrm{a}, *}$ and Christian Antonio ${ }^{2, \mathrm{~b}}$ \\ 1 Department of Chemical Engineering, Faculty of Engineering, Burapha University, Sean Sook, Muang, \\ Chonburi 20131, Thailand \\ 2 Julius Kruttschnitt Mineral Research Centre, Sustainable Minerals Institute, University of Queensland, \\ Indooroopilly, Brisbane, QLD 4068, Australia \\ E-mail: apiyachat.a@eng.buu.ac.th (Corresponding author), bC.antonio@uq.edu.au
}

\begin{abstract}
Variable Frequency Microwave (VFM) is known to be a rapid, volumetric, and selective form of heating which has shown potential as an alternative technique for the processing of negative-tone SU8 photoresist in the Micro-Electro-Mechanical System (MEMS) industry. A comparison of thermal properties of the films cured during the softbake and post exposure bake process using different techniques, i.e. conventional thermal curing, VFM curing, and a combination of both (referred to as hybrid, HY), was investigated using a Differential Scanning Calorimeter (DSC) and Thermogravimetric Analysis (TGA). A significant increase on the degree of cure (between 13-23\%) was observed using the VFM over the hybrid and hotplate curing which means that SU8 curing at lower temperatures or rapid curing is possible. The increase in cure rates can be attributed to a combination of heat transfer and the unique capability of microwave to couple with the sample (selective heating). The improvement in curing at the same processing temperatures has important implications for processing thick films. It was found that regardless of curing methods, crosslink densities increased as the baking temperature increased, resulting in lower dielectric properties. Despite higher crosslinking contents, VFM cured samples decomposed at $2-4^{\circ} \mathrm{C}$ lower temperatures. In addition to better thermal properties, VFM offered satisfactory microstructure at lower curing temperatures; however, high processing temperatures could result in film cracking.
\end{abstract}

Keywords: Variable frequency microwave (VFM), SU8, photoresist, curing, crosslink density, glass transition temperature $\left(T_{\mathrm{g}}\right)$.

ENGINEERING JOURNAL Volume 20 Issue 5

Received 30 November 2015

Accepted 10 March 2016

Published 25 November 2016

Online at http://www.engj.org/

DOI:10.4186/ej.2016.20.5.169 


\section{Introduction}

SU8 is a negative tone, epoxy-based, near-UV $(350-400 \mathrm{~nm})$ photoresists which was first formulated at IBM as early as 1982 and since then it has been widely used in the electrical and electronics industries. It is suitable for various high aspect ratio patterning purposes such as masking for deep reactive-ion etching (RIE), electroplating molds, injection molding masters, microfluidic components and structural parts for micro motors. Its main lithographic application has been in deep optical lithography and $\mathrm{x}$-ray exposures to produce high aspect ratio structures for microelectricalmechanical system (MEMS) and micro-opto-electromechanical systems (MOEMS) applications where the resist is used in very thick films (5-500 $\mu \mathrm{m})$ [1-4]. Currently SU8 has been extended to several applications such as a micro-direct fuel cell (microDMFC) [5], an optical sensor [6], a microscale surface thermometry [7], as well as in medical areas [8,9]. Cured SU8 forms a highly crosslinked matrix of covalent bonds which results in glass like mechanical properties and robust structures $[10,11]$. Other advantages include, relatively low price, the feasibility of batch processing, high thermal stability, good chemical resistance and low optical absorption. SU8 properties are not solely dependent on crosslink density which in turns depends on curing conditions, but also lately there are studies involving SU8 nanocomposites aiming to enhance its performance using nanomaterials [10, 12-15]. Shortcomings of these composites are complication in fabrication as well as high cost.

One of the decisive factors determining the patterning of UV lithography is the prebake of the thick photoresists. The prebake or the softbake (SB) is where much of the solvent has to be evaporated from the coating. This step traditionally requires long bake times and/or high temperatures. These conditions can; however, cause degradation of the photoactive compound as a consequence hence affecting the function of the resists layer. The long softbaking and curing times together with the mismatch in coefficient of thermal expansion (CTE) between SU8 and its substrate, and the characteristically inherent rigid molecular structure of the molecule combine to generate considerable internal stress which causes cracked lithographic features $[2,16]$. Amato et al. [17] concluded that soft and post-baking at a low temperature for a long time was necessary for a high structure stability. Alternative processing methods for SU8 has been investigated to speed up the process and to avoid abnormalities in the structures such as cracks. These include nonconventional curing such as IR baking and hybrid curing methods using a combination of hotplate and IR energy. IR energy is absorbed by the resist which causes uniform heating of the resist layer thus, reduction of process time and temperature has been observed $[18,19]$.

Although there have been a number of studies related to microwave (MW) curing of epoxy based polymers, there has been very little done in terms of microwave curing of photoepoxies and even less on studies using variable frequency microwave (VFM). VFM uses a broadband of frequencies as opposed to the conventional single-fixed frequency method. This technology obtains a time-average power uniformity within the microwave cavity and has been able to overcome many of the inherent problems associated with conventional microwave processing such as heat uniformity and the ability to process metals. Providing the same curing time, the lap shear strengths of glass fiber reinforcing polystyrene cured by VFM were higher than those cured by a fixed frequency MW due to the fact that the material was able to selectively absorb certain MW frequency [20]. Similar results of higher lap shear strengths of carbon nanotube reinforcing epoxy of MW curing in comparison to thermal curing were observed [21]. A study by Farnsworth et al. [22] investigated VFM for rapid curing of two photosensitive polyimides, polymer dielectrics which are widely used in the microelectronics industry for a variety of applications. Their results indicate that VFM is a feasible alternative method for processing these type of polymers. Rapid curing of approximately 12-30 minutes where achieved for VFM as compared to 240-300 minutes for thermally cured samples. However, a significant difference in electrical properties was obtained due to the completely different heating mechanism under microwave radiation and conventional heating which caused slow evolution and incomplete removal of volatile reaction by-products during VFM cure. In addition, the chemical structures of polymers cured by VFM were identical to those of conventionally thermal curing [20, 22-23]. The enhancement of mechanical properties of thermosets and polymer composites by MW curing was partly due to the enhancement of crosslink densities, glass transition temperature $\left(T_{g}\right)$ and better interfacial bonding between the matrix and the reinforcing fibers [23-26]. A slight difference in molecular structure of MW cured carbon fiber/epoxy composite was observed and hypothesized as a cause of $\mathrm{T}_{\mathrm{g}}$ increment though the percent cure were comparable, resulting in the improvement in specific compressive strength of the composites [24]. It was speculated that while carbon nanotubes obstructed polymer chain movement and hence impeded crosslinking during thermal heating, microwave energy preferentially heated the carbon 
nanotubes imbedded in the composites and allowed the epoxy to crosslink around the carbon nanotube/epoxy interfaces, causing higher crosslink density and $\mathrm{T}_{\mathrm{g}}$ of the MW cured composites [21, 25]. However, there was a contradicting report that suggested that with a comparable degree of curing, MW curing did not have a significant effect on $\mathrm{T}_{\mathrm{g}}$ though they also found a higher percent cure of epoxy resin with MW curing at the same curing temperature and time with the thermal curing [23]. It was revealed that MW curing could lower the activation energy of furan resins by $13 \%$ and hence increase the reaction rate; however, the reaction mechanism was unchanged [26]. An even MW energy distribution was one of the main MW curing characteristics that is required in order to achieve good mechanical properties materials and possibility of scaling up the process and one way to obtain the homogeneous MW energy fields was to use the VHM which is a MW having 12 magnetrons operating at a frequency of $2.45 \mathrm{GHz}$ [25]. Accordingly, this study is aimed to extend the VFM which also generating a uniform heating to the processing of SU8.

\section{Experimental}

\subsection{SU8-2100}

SU8 is a negative type photoresist, prepared from the epoxy-based EPSON SU8 dissolved in an organic solvent. It has been commercially available for MEMS production and can be used in several processes. SU8 monomer has eight epoxide functionality per molecules as shown in Fig. 1 which is a result of epoxidation of novolac resin formed from the condensation polymerization of bisphenol A and formaldehyde. SU8-2100 used cyclopentanone as a solvent and a triaryl salt $\left(\mathrm{SbF}_{6}\right)$ as a photoacid generator (curing agent) as illustrated in Table 1. Once the SU8 monomers are exposed to UV irradiation, the photoacid initiates the crosslinking process which is thermally driven during Post Exposure Bake (PEB), details of which is elaborated upon in the next section. The photoacid is considered as a catalyst as it is not be consumed during the reaction and can initiate several chains, resulting in a rigid SU8 polymer where an epoxy monomer is connected to an average of seven other monomer.

Table 1. SU8-2100 formulation.

\begin{tabular}{llc}
\hline Composition & CAS no. & Content (\%) \\
\hline SU8 & $28906-96-9$ & 75 \\
Cycloheptanone & $120-92-3$ & 24.5 \\
mixed triarylsufonate/hexafluoroantimonate salt & $89452-37-9 / 71449-78-0$ & 0.5 \\
\hline
\end{tabular}

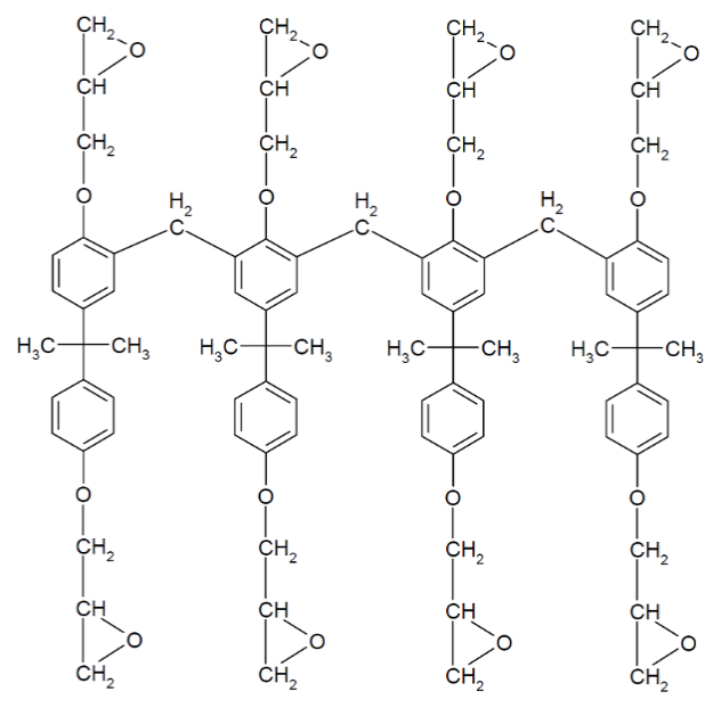

Fig. 1. SU8 monomer. 


\subsection{Photoresist Preparation}

Figure 2 is a schematic diagram of photolithography steps involving photoresist. The process started from deposition of SU8 monomer on a boron doped silicon $<100>$ wafer obtained from Motorola using a spin coating technique. Prior to the spin coating process, the substrate was dehydrated in an oven at $150^{\circ} \mathrm{C}$ for 15 min. Spin coating conditions (speed and time) depends on viscosity of the photoresist and in this work $260 \mu \mathrm{m}$ was the resulting thickness of the photoresist film. The spun film was allowed to settle for a few minutes on a levelled surface before going to the next step of Softbake (SB). The SB was a step for evaporating the solvent as well as for densifying the film. The time and temperature profile of the SB process is illustrated in Fig. 3 and is the same for both heating techniques, i.e. a conventional curing by hotplate (HP) and VFM curing using a MicroCure 2100 variable frequency microwave system from Lambda Technologies. As SU8 is sensitive in the near-UV region $(365 \mathrm{~nm})$, the film was exposed to UV irradiation (275W UV lamp) which translates to an intensity of approximately $15-20 \mathrm{~mW} / \mathrm{cm}^{2}$ at a pressure of $350 \mathrm{mmHg}$ for $120 \mathrm{sec}$ using a broadband mask aligner in order to initiate crosslinking of SU8 in the exposed region. The curing was continued during the PEB in which the bake temperature must be greater than the glass transition temperature $\left(\mathrm{T}_{\mathrm{g}}\right)$ of the unexposed film which is $50^{\circ} \mathrm{C}$ in this case. At this stage, 4 PEB temperatures, i.e. $65,75,85$, and $95^{\circ} \mathrm{C}$, and 2 heating techniques, i.e. HP and VFM, were studied as shown in the time-temperature profile in Fig. 3. As HP and VFM were both used in the SB and PEB steps, there were 3 pathways of the heating methods as shown in Table 2 where hybrid (HY) technique refers to a combination of using HP during SB and VFM during PEB. Finally, the film underwent a development step by means of immersion method using MicroChem SU8 developer (propylene glycol methyl ether, PGME). The substrate was immersed in the developer at room temperature for a several minutes, followed by an isopropyl alcohol (IPA) rinse and nitrogen stream drying.

\begin{tabular}{|c|c|c|c|c|}
\hline Deposition & Softbake (SB) & UV Exposure & $\begin{array}{l}\text { Post Exposure } \\
\text { Bake (PEB) }\end{array}$ & Development \\
\hline spin coating & $\begin{array}{l}60 \mathrm{~min} \text { holding } \\
\text { time at } 95^{\circ} \mathrm{C} \text { by } \\
-\quad \text { HP or } \\
-\quad \text { VFM }\end{array}$ & $\begin{array}{l}2 \min \\
275 \mathrm{~W}, 365 \mathrm{~nm}\end{array}$ & $\begin{array}{l}15 \mathrm{~min} \text { holding } \\
\text { time at } \\
65 / 75 / 85 / 95^{\circ} \mathrm{C} \\
\text { by } \\
- \text { HP or } \\
-\quad \text { VFM }\end{array}$ & $\begin{array}{c}\text { MicroChem SU8 } \\
\text { developer }\end{array}$ \\
\hline
\end{tabular}

Fig. 2. Schematic diagram of processing of SU8 photoresist in this study.

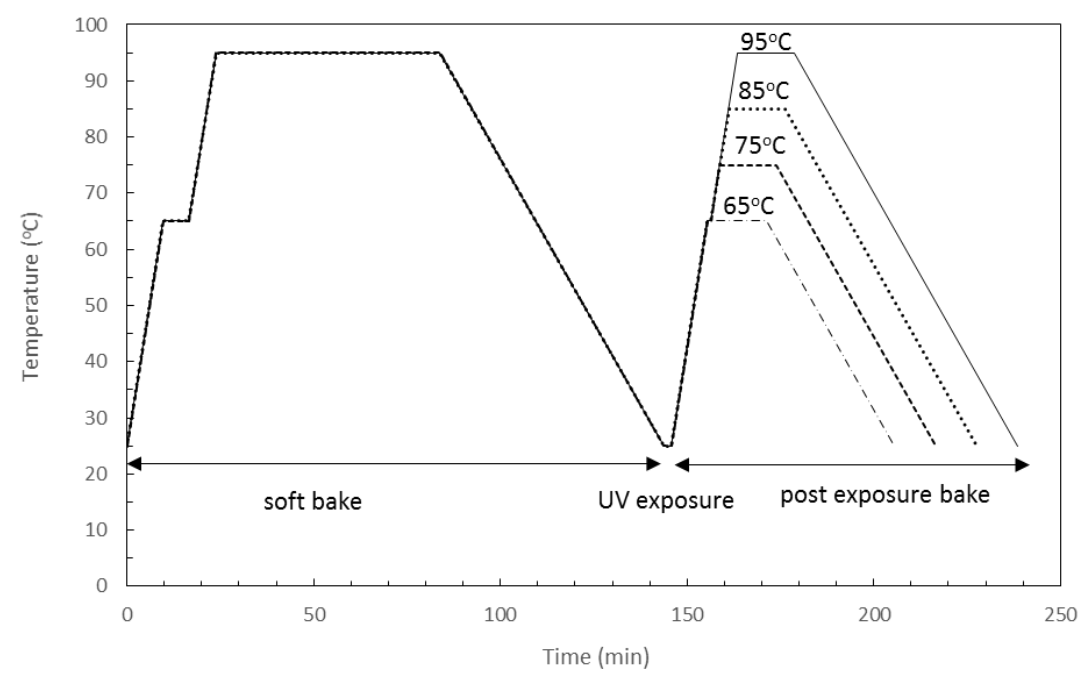

Fig. 3. Time-temperature profile of SB and PEB steps. 
Table 2. Heating pathway using HP and VFM techniques.

\begin{tabular}{lcc}
\hline Heating pathway & $\mathrm{SB}$ at $95^{\circ} \mathrm{C}$ & PEB \\
\hline HPXX & $\mathrm{HP}$ & $\mathrm{HP}$ at $\mathrm{XX}{ }^{\circ} \mathrm{C}$ \\
HYXX & $\mathrm{HP}$ & VFM at $\mathrm{XX}^{\circ} \mathrm{C}$ \\
VFMXX & $\mathrm{VFM}$ & VFM at $\mathrm{XX}^{\circ} \mathrm{C}$ \\
\hline
\end{tabular}

Curing of SU8 thick film of $>500 \mu \mathrm{m}$ was also attempted in order to determine and compare the ability of the two heating techniques to process thick films. Since the film was considerably thick, the film preparation procedure was adjusted for an appropriate condition by increasing SB and PEB holding periods to 720 and $30 \mathrm{~min}$, respectively. Furthermore, as the film was too thick for UV mask aligner, the UV exposure was performed without the pattern. Only the PEB temperature of $95^{\circ} \mathrm{C}$ was carried out and the HY pathway was not attempted.

\subsection{Photoresist Characterization}

To understand the effects of microwave energy on the SU8 and hence the heat absorption mechanism, dielectric measurement were carried out using a Dielectric Probe kit coupled to an Agilent S-Parameter Network Analyzer (Model 8722ES) with an operating bandwidth of $50 \mathrm{MHz}-40 \mathrm{GHz}$. Prior to taking dielectric measurements, the dielectric probe was calibrated against substances with known dielectric properties. These were air, distilled water and a metallic shorting block. Dielectric constant and dielectric loss were taken at $2.45-8.0 \mathrm{GHz}$ at $25^{\circ} \mathrm{C}$. Appropriate care was taken not to introduce bubbles in the liquid uncured SU8 and calibration water whilst calibrating the system and whilst taking readings. For solid cured SU8 samples, it was ensured that the probe face was resting parallel to the cured film and had good contact without any gaps.

A Differential Scanning Calorimeter from Mettler Toledo (DSC 821e) was used to study the thermal calorimetric properties of the cured and uncured resin and monitor the curing process via measurement of the heat of reaction. SU8 samples between 5-10 $\mathrm{mg}$ were enclosed in a 40 microlitre aluminium pan with a pierced lid to prevent excessive pressures from building up during the solvent evaporation phase and were tested under a nitrogen purge of $50 \mathrm{ml} / \mathrm{min}$ to inhibit oxidation during heating. Samples were heated at a rate of $10^{\circ} \mathrm{C} / \mathrm{min}$ to a temperature just below the degradation temperature of $380^{\circ} \mathrm{C}$ [1]. The extent of cure (\% cure) was calculated as per Eq. (1)

$$
\% \text { cure }=\frac{\left(\Delta H_{\text {uncured }}-\Delta H_{\text {cured }}\right)}{\Delta H_{\text {uncured }}} \times 100
$$

where $\Delta \mathrm{H}_{\text {uncured }}$ is the heat of cure of the unreacted SU8 resin and $\Delta \mathrm{H}_{\text {cured }}$ is the heat of cure of the partially cured sample. The heat of cure was normalized by the mass of each sample.

Thermogravimetric Analysis (TGA) was conducted using a Mettler Toledo TGA850 Thermal Analyzer to study sample thermal stability and weight loss as a function of time and temperature. SU8 samples were contained in a 70 microlitre alumina crucible and heated using a ramp rate of $10^{\circ} \mathrm{C} / \mathrm{min}$ from room temperature to a temperature of $1000^{\circ} \mathrm{C}$ in a nitrogen atmosphere. The degradation temperatures, $\mathrm{T}_{\mathrm{d}}$, are evaluated from the peak from Derivative Thermogravimetric Analysis (DTG) and compositions in the sample are determined from weight loss.

After development of the thin SU8 films, film thickness and surface profile of the samples were obtained using a Mahr Perthometer Profilometer whereas the microstructures were inspected using a Laser Scanning Confocal Microscope and a standard optical microscope both from Olympus. 


\section{Results and Discussions}

\subsection{Preliminary Study on Dielectric Properties}

\subsubsection{Dielectric properties of uncured SU8, solvent, and substrate}

The set-up for dielectric properties measurement was tested against the known samples of water and acetone and the results in Table 3 suggested an acceptably good agreement with less than $10 \%$ deviation of the literature values suggesting good equipment calibration. Figure 4 shows that dielectric loss of uncured liquid SU8-2100 was low at around the value of 1.3 and considerably constant over the ranged of MW frequencies used $(2.45-8 \mathrm{GHz})$ compared to those of cyclopentanone and silicon wafer, implying that the material is not MW absorbing which is characteristics of most polymeric materials. On the other hand, dielectric loss of cyclopentanone increased with MW frequency and was higher than that of SU8 and up to four times of the value at $8 \mathrm{GHz}$. Thus, one would expect the photoresist to absorb microwave radiation but since the photoresist contained only a small amount of the solvent, the overall microwave absorption capacity can also be expected to be small. Dielectric loss of silicon wafer was also higher than that of SU8 but lower than that of cyclopentanone, and fairly constant at around 4. The dielectric loss factor of the substrate is several times that of the bulk SU8 which means that most of the microwave absorption will be by the substrate.

Table 3. Validation of dielectric properties measurement set-up.

\begin{tabular}{lcccc}
\hline Known samples & Dielectric properties & Measured Value & Literature Value & $\%$ Difference \\
\hline Water & $\varepsilon^{\prime}$ & 79.9 & 80 & $0.13 \%$ \\
& $\varepsilon^{\prime \prime}$ & 5.63 & 6.1 & $7.7 \%$ \\
\hline Acetone & $\varepsilon^{\prime}$ & 22.1 & 20.7 & $6.8 \%$ \\
& $\varepsilon^{\prime \prime}$ & 1.1 & - & - \\
\hline
\end{tabular}

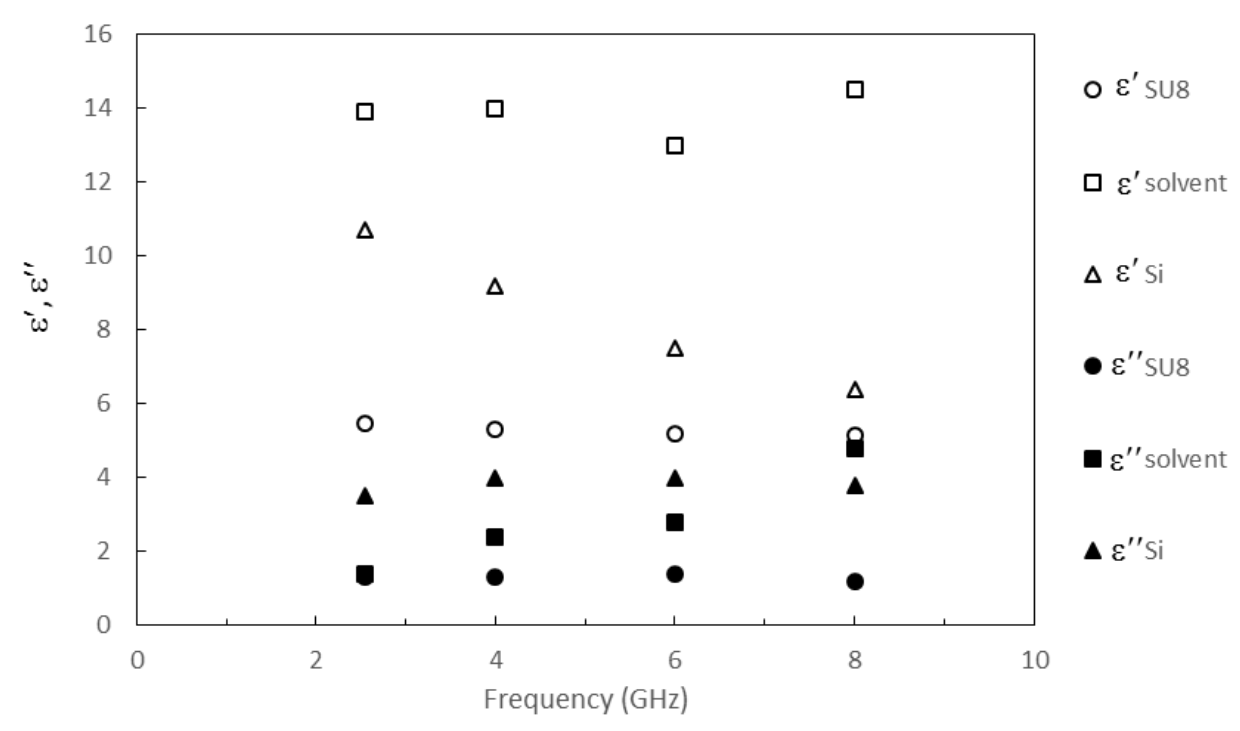

Fig. 4. Dielectric properties of monomer SU8, cyclopentanone, and silicon wafer over a range of MW frequency of $2.45-8 \mathrm{GHz}$.

The dielectric properties in Fig. 4 were obtained at a constant temperature of $25^{\circ} \mathrm{C}$; however, it is well known that dielectric properties could be temperature dependent. Since the temperature was constantly changing during MW processing, the dielectric properties are also expected to constantly change. Thus, dielectric properties were measured at different temperatures ranging from $25-100^{\circ} \mathrm{C}$ at two different frequencies of 2.45 and $3.5 \mathrm{GHz}$ to determine how they changed with temperature and frequency. An enclosed heating apparatus especially designed for liquids was used as a heat source whilst dielectric 
measurements were being taken. The results (shown elsewhere) demonstrated that SU8 was not MW absorbing since the dielectric properties of SU8 did not vary considerably with temperature over the range studied and were comparable at the two frequencies, confirming the results in Fig. 4 that they were frequency independent.

\subsubsection{Temperature rise during VFM process}

As the MW operates at a certain frequency and power, or over a range of frequency in the case of VFM, there must be a change of temperature due to the effect of dielectric properties of the heating materials over the heating period. The heating behaviors of the liquid SU8 and the silicon substrate was investigated to determine the individual heating abilities of each. A fiber optic temperature probe was used to determine the temperature change and was attached to the samples using kapton tape. Temperature profiles were gathered using the inbuilt data acquisition hardware of the VFM. In order to investigate the heating profiles for SU8, a glass substrate was used as it is virtually transparent to microwave energy and will not substantially contribute to the rise in temperature of SU8. The temperature profiles for the SU8 by itself shown in Figs. 5 and 6 suggested and supported the dielectric measurements undertaken that it was not very susceptible to microwave energy as the maximum temperature rise obtained over a $120 \mathrm{sec}$ interval is only approximately $4{ }^{\circ} \mathrm{C}$ even for the highest power used of $150 \mathrm{~W}$. It did show however that it was more MW absorbing at higher powers $(100$ and $150 \mathrm{~W})$ and higher frequencies $(6$ and $8 \mathrm{GHz})$. This temperature rise is most likely due to the solvent component (cyclopentanone) of the SU8 which was found to be more susceptible to microwave power between $6-8 \mathrm{GHz}$ as discussed previously.

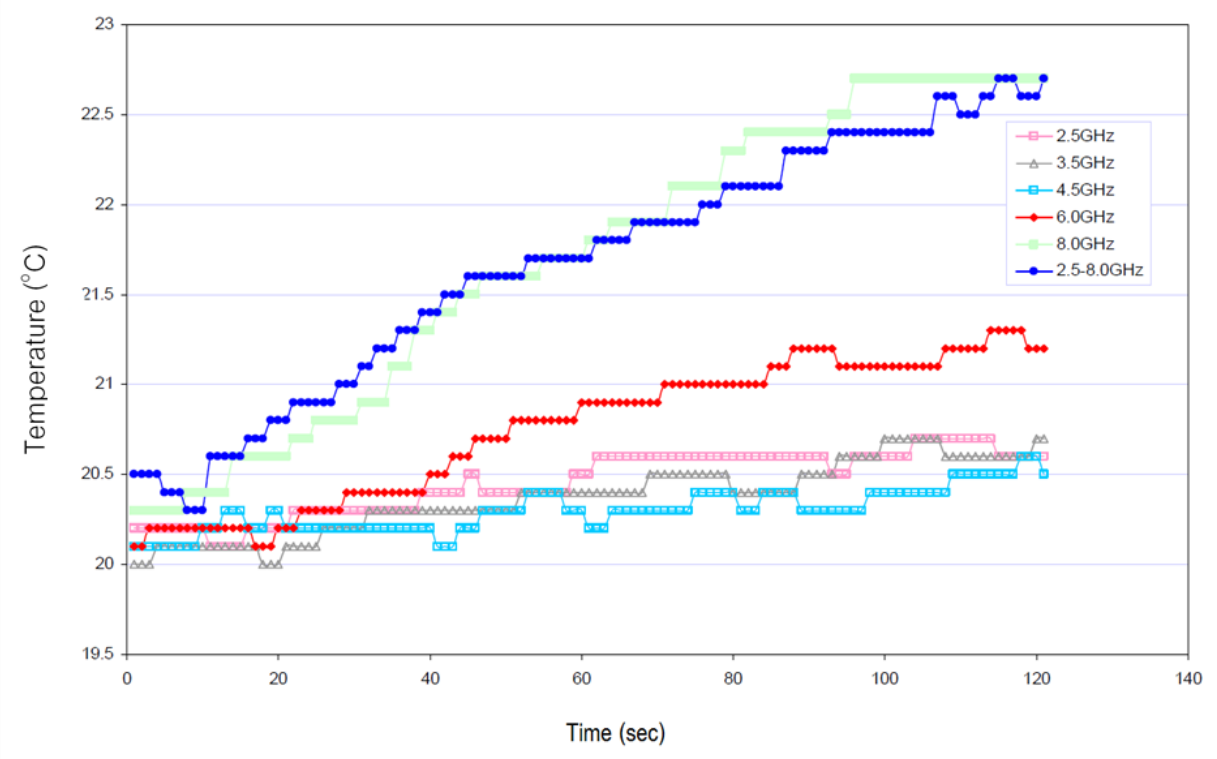

Fig. 5. Effects of MW frequency on temperature rise of SU8 on glass substrate at MW power of $50 \mathrm{~W}$. 


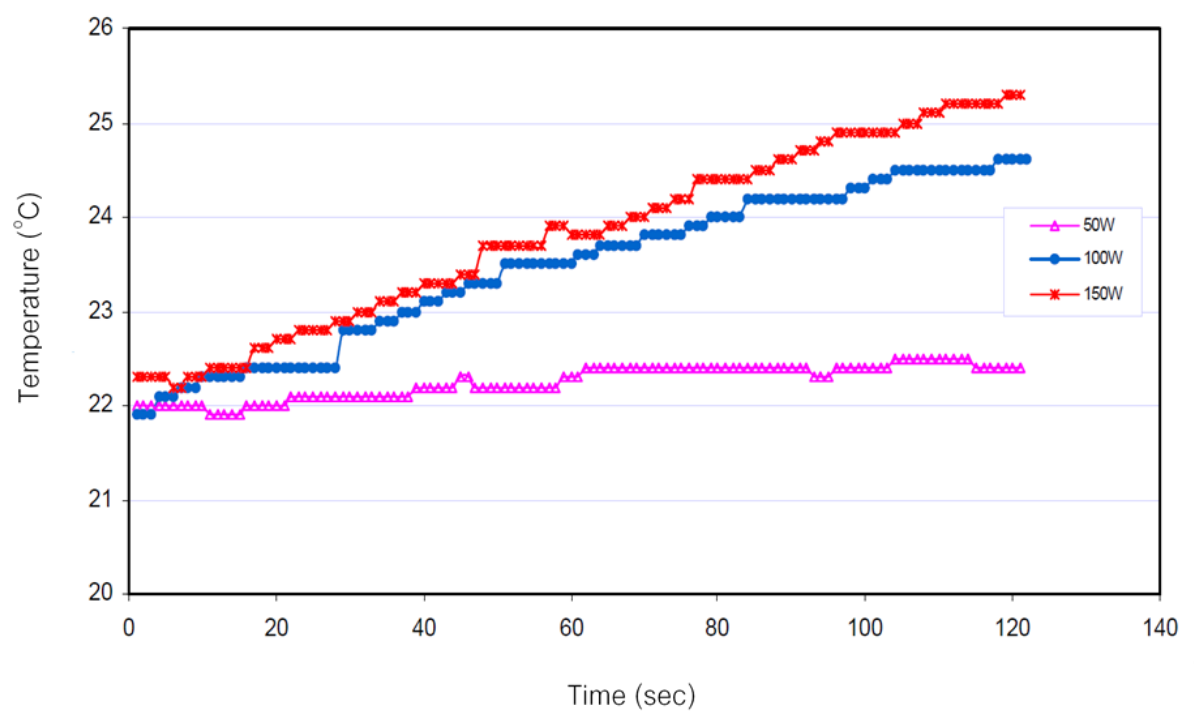

Fig. 6. Effects of MW power on temperature rise of SU8 on glass substrate at a frequency of $2.5 \mathrm{GHz}$.

As it was shown previously that silicon wafer substrate had a higher dielectric loss than the bulk SU8, temperature rise during the MW operation was significantly higher than that of SU8. The heating profiles illustrated in Fig. 7 show that the substrate strongly absorbed energy at 3.5 and $4.5 \mathrm{GHz}$ which resulted in the highest temperature rise and the lowest occurring at $2.5 \mathrm{GHz}$. The heating profiles showed that the temperature rose rapidly at the initial state and gradually increased as fast as $50 \mathrm{sec}$. Figure 8 illustrates the temperature rise as a function of MW power. Results showed that the rate of initial temperature rise was proportional to the power input. As expected, a higher input power generated a more rapid ascent to the final temperature as well as achieving a greater temperature rise. This also showed that for a particular power, there was a limit to the maximum temperature that can be achieved due to heat losses.

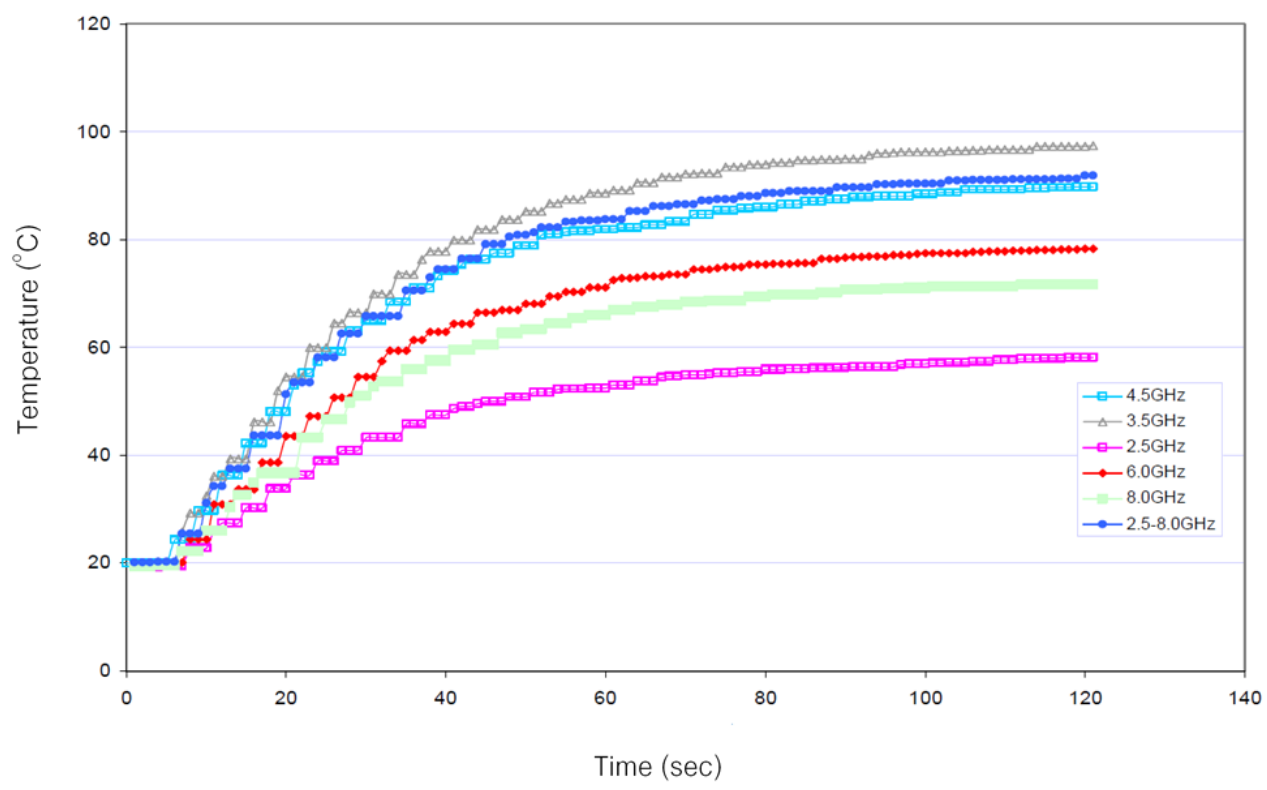

Fig. 7. Effects of MW frequency on temperature rise of silicon substrate at MW power of $50 \mathrm{~W}$. 


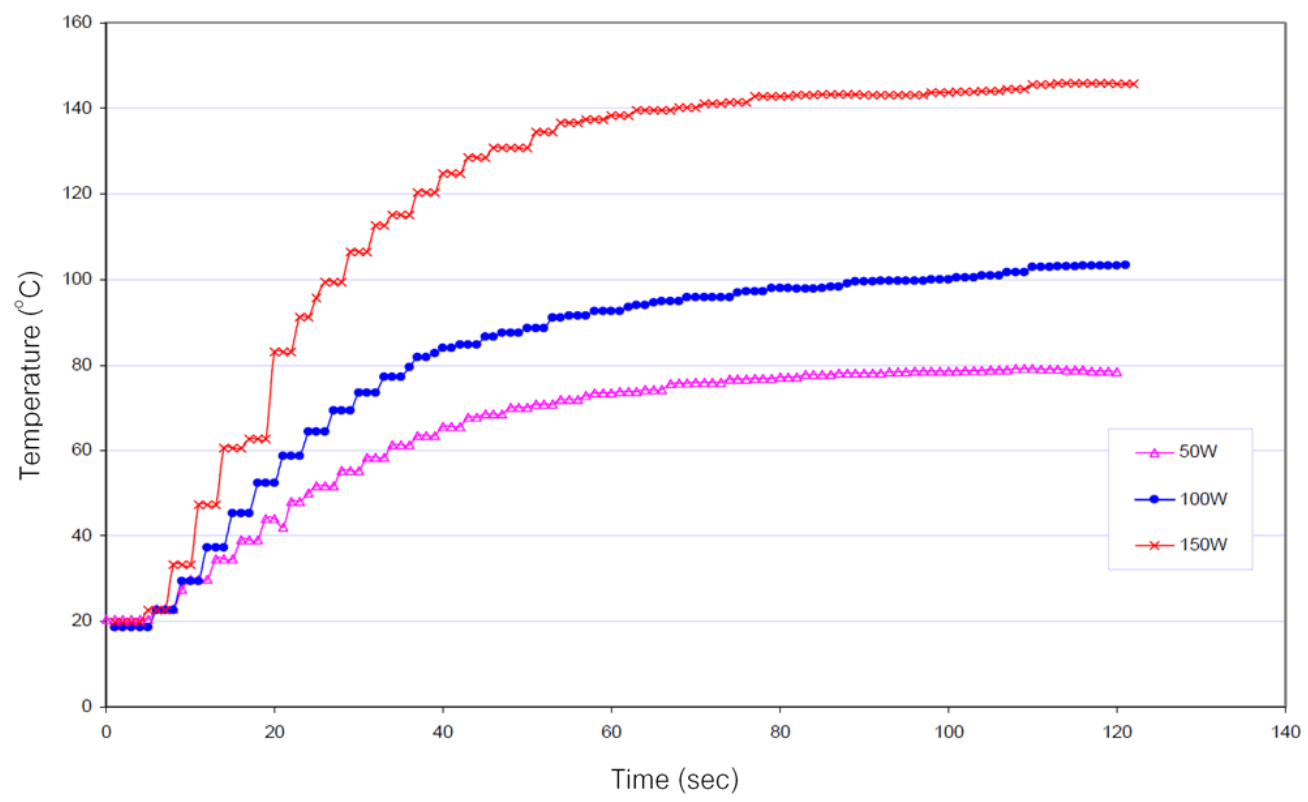

Fig. 8. Effects of MW power on temperature rise of silicon substrate at a frequency of $2.5 \mathrm{GHz}$.

\subsection{Dielectric Properties of Cured Samples}

The dielectric properties for SU8 cured by different curing pathways were evaluated and compared to the dielectric properties of an uncured SU8 at the conventional microwave frequency of $2.45 \mathrm{GHz}$ and the results were shown in Fig. 9. During a curing process, the polymers dielectric constant, which is a measure of the ability to absorb microwaves, vary as phase changes within the polymer occur. In thermosetting polymers, the viscosity and molecular weight increase during the cure as their crosslinked densities increase. Studies have shown that the permittivity (dielectric constant) and the dielectric loss factor of these polymers generally increase with temperature and decrease with extent of cure [27]. Thus, initially thermosets are an efficient absorbers of microwave energy as the dielectric loss factor increases as temperature increases. However, as the polymer crosslinks the materials become relatively less and less susceptible to microwave heating owing to the decrease in dipolar mobility and, hence, dielectric properties with extent of reaction. During the SB and PEB, initial curing involves the gelation of the liquid SU8 to form longer but initially linear chains, thus resulting in an increase in viscosity but not entanglement of the growing chains. As the curing process proceeds, the entanglements increase significantly to isolate the reactive epoxy groups within the matrix, together with some of the residual protons and any other reactive species. As the curing proceeds the epoxy groups decrease hence the lower dielectric loss factor measured for the HY and VFM samples.

For the HP samples, it seems that a decrease in dielectric loss factor does not occur until a processing temperature of $95^{\circ} \mathrm{C}$ is used. The initial increase in dielectric loss factor may be due to the residual solvent and photoproducts such as radical initiators generated during UV exposure, remaining in the film. Any retained solvents and residual curing agent would result in higher dielectric properties. The presence of these retained species are observed as the initial weight loss detected in the TGA results of the cured samples as discussed in the next section. Although the weight loss is also observed in the HY and VFM cured samples, any retained solvents and residual curing agent did not increase the measured dielectric loss factor as the molecular structure of the polymer were already rigid due to the higher degree of cure achieve using these methods compared to HP processing. In general, the dielectric loss factor decreases with the processing temperature as seen in Fig. 9 for each processing method which is expected. 


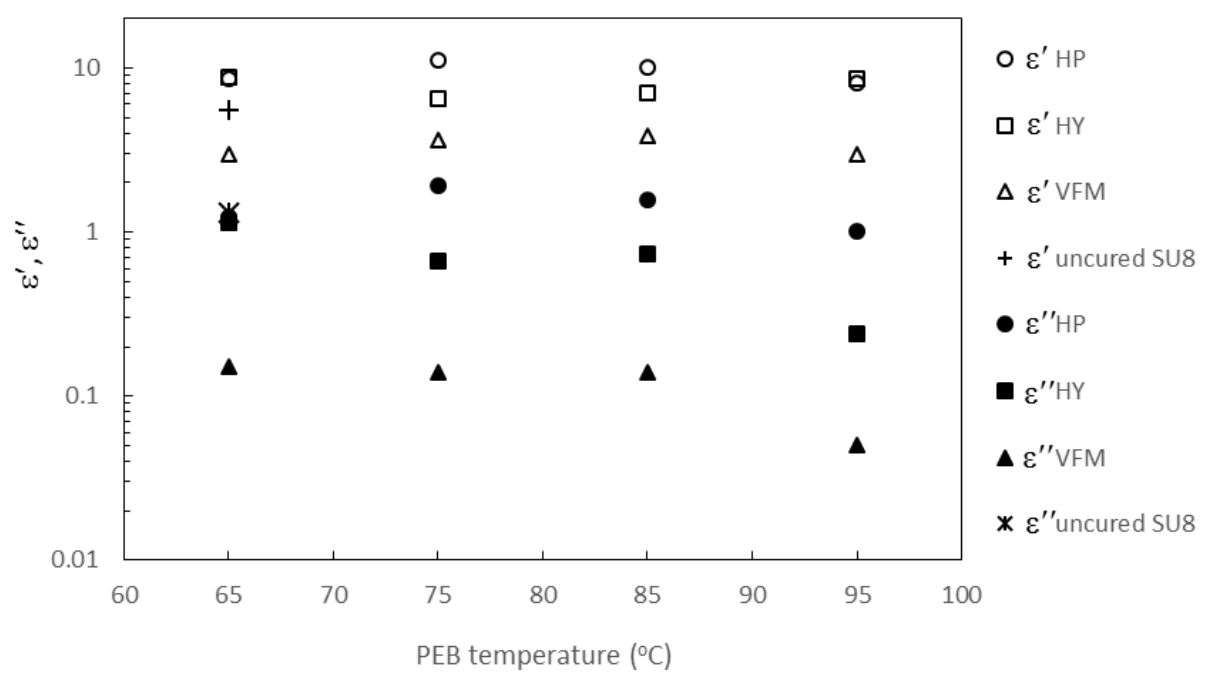

Fig. 9. Dielectric properties of cured SU8-2100 samples under different curing pathways.

\subsection{Thermal Properties of Cured Samples}

\subsubsection{Degree of curing}

A DSC analysis was carried out on the as supplied SU8 resin to determine the heat of cure of the unreacted resin $\left(\Delta \mathrm{H}_{\text {uncured }}\right)$ and it was found to be $252 \mathrm{~J} / \mathrm{g}$. The curing reaction was found to start at around $150^{\circ} \mathrm{C}$ with two large exothermic peaks at approximately 220 and $300^{\circ} \mathrm{C}$ as can be seen in Fig. 10 . The end of the reaction was observed at $\sim 350^{\circ} \mathrm{C}$, slightly lower than an onset temperature of degradation of $380^{\circ} \mathrm{C}$ found from a TGA analysis which will be discussed later on. Similar exothermic peaks were also found from cured samples; however, as the degree of curing increased, the second peak seemed to be smaller for HP and HY techniques and disappeared for VFM technique. The large exothermic peaks found indicated that the films were not fully cured during the PEB. This result is common with the findings of other researchers [28] whose studies have found that the disappearance of this exothermal peak was only observed after the hard bake which was not undertaken in this study. Typically, a hard bake is undertaken at a temperature of $>200^{\circ} \mathrm{C}$ to fully crosslink the polymer.

In all the DSC curves, a small endothermic peak at approximately $70-80^{\circ} \mathrm{C}$ can be observed and is possibly due to moisture and trapped solvents within the densified film. Unlike the uncured SU8, the onset and endset temperatures of the curing process started and finished earlier at 100 and $270^{\circ} \mathrm{C}$, respectively, due to the fact that the samples were partially thermally cured. Figure 11 shows that the degree of cure increases with increasing PEB temperature for all curing techniques. At the same PEB temperature, the conventional (HP) curing was found to achieve the lowest percents cure while VFM curing resulted in the highest percents cure which were in the range of $15-23 \%$ higher than those of HP curing. The percents cure of HY curing were 2-6\% higher than those of HP curing. The higher conversion rates obtained during the HY and VFM processing exemplify the advantage of MW energy in polymer processing and its major effect on curing rates of SU8. The increase in curing rates over the conventional HP curing maybe explained in two ways. One is a purely heat transfer explanation and the other brought about by the unique ability of MW energy to couple with the sample. This hypothesis will be discussed later on along with the discussion of the thickness profile measured from a profilometer. 


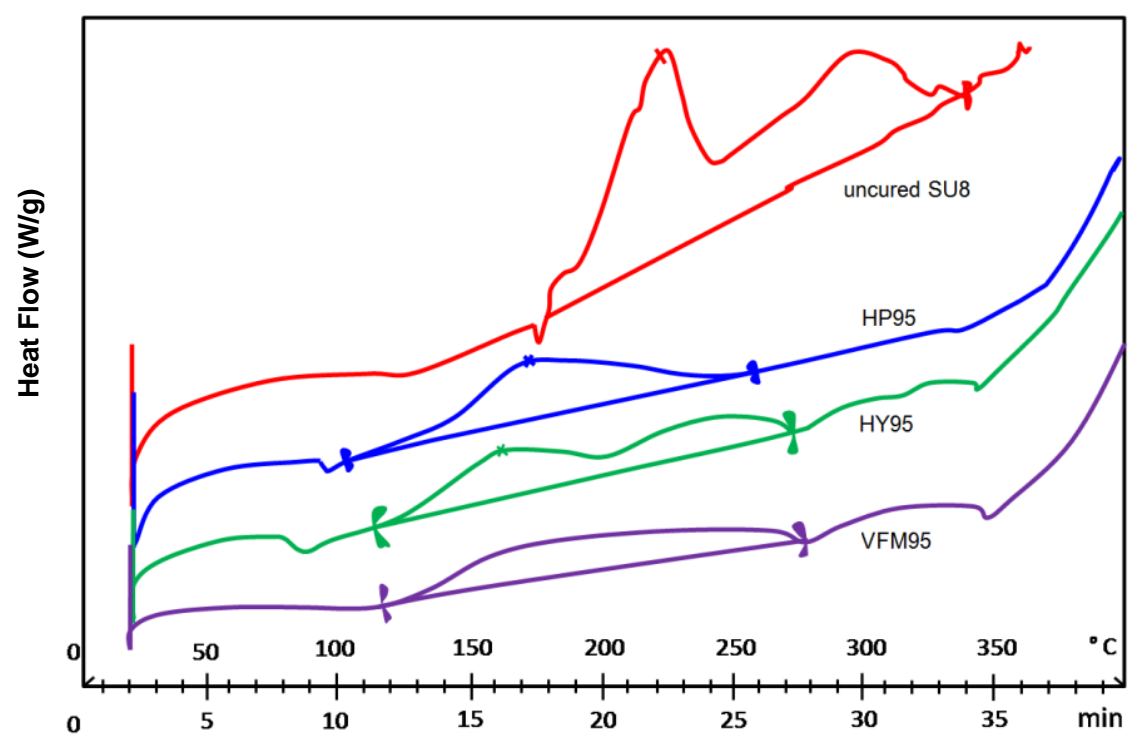

Fig. 10. DSC thermogram of uncured and cured SU8.

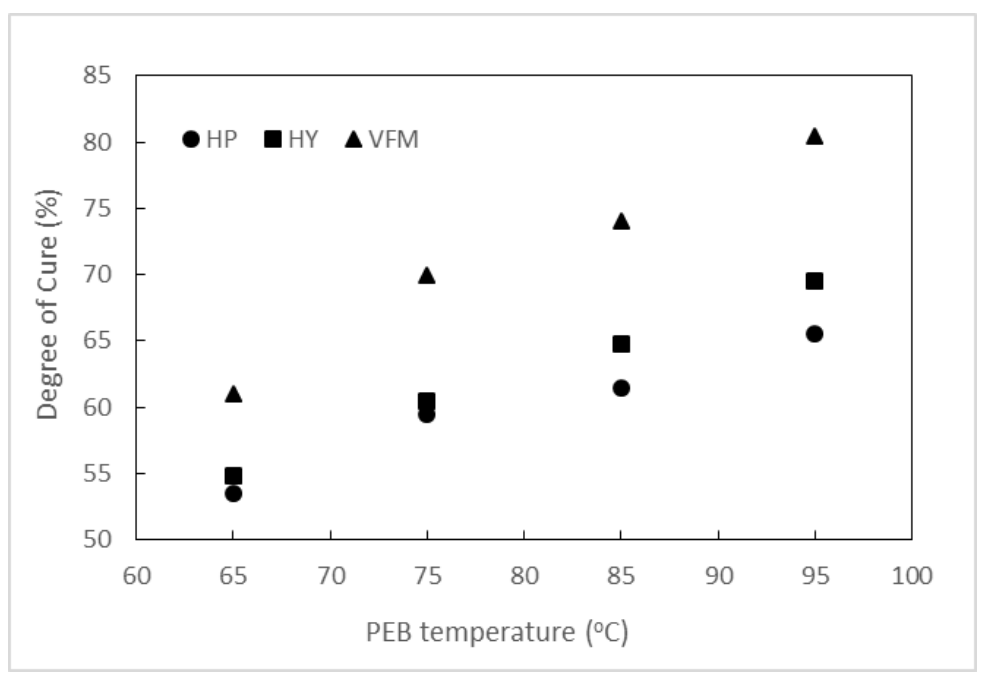

Fig. 11. Degree of cure of SU8 cured by different pathways.

\subsubsection{Glass transition temperature}

Several attempts had been undertaken to determine the glass transition temperatures $\left(\mathrm{T}_{\mathrm{g}}\right)$ of cured SU8; unfortunately the large exothermic curing peak overlaps with $T_{g}$ which was similar to the findings of Johnston et al. [23]. Different $\mathrm{T}_{\mathrm{g}}$ has been reported in literature due to the differences in processing conditions. However, the reported $\mathrm{T}_{\mathrm{g}}$ for a fully cured, hardbaked, SU8 films is over $200^{\circ} \mathrm{C}$ [29]. Feng and Farris [28] found that the $T_{g}$ is approximately identical to the baking temperature when the processing temperature is less than $220^{\circ} \mathrm{C}$ and increasing in deviation at higher temperature ranges to a maximum $\mathrm{T}_{g}$ of $238^{\circ} \mathrm{C}$ at a baking temperature of $300^{\circ} \mathrm{C}$, which corroborates with the finding of LaBianca [29]. The $\mathrm{T}_{g}$ of post cured SU8 films has been reported to be always higher than the PEB curing temperature of about $40-70^{\circ} \mathrm{C}[30]$.

The $T_{g}$ is uniquely related to the conversion for a thermosetting system. Di Benedetto has derived from theory an equation relating the shift in the $\mathrm{T}_{\mathrm{g}}$ temperature to the degree of crosslinking [31]. By assuming an idealized system consisting of a mixture of a fully cured network and an unreacted monomer phase, a more commonly used version of the well-known Di Benedetto equation was derived from entropic considerations as shown in Eq. (2) [32]. 


$$
\frac{T_{g}-T_{g o}}{T_{g \infty}-T_{g o}}=\frac{\lambda \alpha}{1-(1-\lambda) \alpha}
$$

where $\alpha$ is the degree of polymer conversion or degree of cure, $T_{g o}$ and $T_{g}$ are the $T_{g}$ values at zero and $100 \%$ conversion respectively and $\lambda$ is an adjustable structure dependent parameter which was found to be $\sim 0.88$ by Rath et al. [2004] for SU8. Using this modified Di Benedetto equation and the results of the degree of cure obtained from the DSC studies, the glass transition temperature for the cured SU8 films were calculated and shown in Fig. 12. The value for $\mathrm{T}_{\text {go }}$ was $50^{\circ} \mathrm{C}$ which was previously measured for the uncured SU8 resin using the DSC, and the reported literature value of $\mathrm{T}_{\mathrm{g}_{\infty}}=238^{\circ} \mathrm{C}$ for a fully cured SU8 [28] was utilized for $\mathrm{T}_{\mathrm{g}}$ prediction.

The prediction of $\mathrm{T}_{\mathrm{g}}$ shows that it increases with increasing PEB temperature as expected and is generally associated with a higher degree of crosslinking attained at higher processing temperatures. The Di Benedetto Model predicted a range of $\mathrm{T}_{\mathrm{g}}$ values between $144^{\circ} \mathrm{C}$ for a conversion of about $53 \%$ at $65^{\circ} \mathrm{C}$ PEB temperature, to $197^{\circ} \mathrm{C}$ for the highest degree of conversion attained of $80 \%$ at $95^{\circ} \mathrm{C}$ PEB temperature. On average, the $\mathrm{T}_{\mathrm{g}}$ values for VFM processed samples are higher than the other processing methods by approximately $14-30^{\circ} \mathrm{C}$. The difference in $\mathrm{T}_{\mathrm{g}}$ reflects the high amount of crosslinking in the VFM cured films as compared to the HP and HY samples at similar PEB temperatures. Predicted $\mathrm{T}_{\mathrm{g}}$ values for $\mathrm{HP}$ and HY films are more or less identical, but as the processing temperatures became greater the differences became larger. An interesting observation may be made about the values of the $\mathrm{T}_{\mathrm{g}}$ predicted and the PEB temperatures used in the experiments. It can be observed that the $\mathrm{T}_{\mathrm{g}}$ is always higher than the PEB temperatures by about $80^{\circ} \mathrm{C}$ for the $\mathrm{HP}$ and $\mathrm{HY}$ processed samples and approximately $100^{\circ} \mathrm{C}$ for the VFM samples. Similar findings have been made by Rath et al. [30] who reported $\mathrm{T}_{\mathrm{g}}$ of about $40-70^{\circ} \mathrm{C}$ above the PEB temperature. The $T_{g}$ values predicted by the Di Benedetto equation seem to be reasonable, although maybe higher than those found in literature. The difference between the predicted and literature values may be due to the differences in processing conditions used.

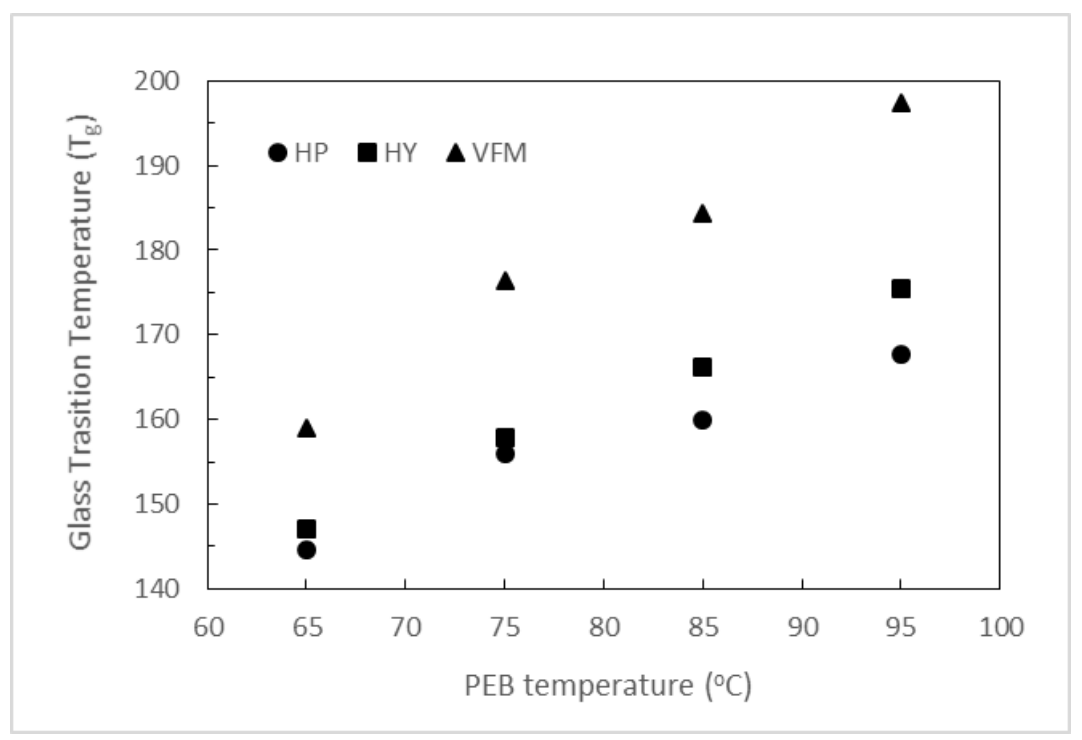

Fig. 12. Prediction of glass transition temperatures of cured SU8-2100 samples under different curing pathways.

\subsubsection{Degradation temperature}

The thermal stability of the uncured SU8 was studied by TGA and their DTG thermogram is presented in Fig. 13. It can be observed that there were two distinct weight loss regions, a broad peak at around $120-$ $180^{\circ} \mathrm{C}$ and a sharp peak at $435^{\circ} \mathrm{C}$. The first transformation may be due to solvent evaporation and decomposition of the curing agent. The weight loss due to material decomposition is $\sim 20 \% \mathrm{w} / \mathrm{w}$ which is close to the original $25 \% \mathrm{w} / \mathrm{w}$ solvent content in the liquid SU8-2100. The second transformation corresponds to the epoxy content which is measured to be $\sim 56 \% \mathrm{w} / \mathrm{w}$ and the remainder being the char content $(24 \% \mathrm{w} / \mathrm{w})$ which is the residual material that could not be decomposed at $1000^{\circ} \mathrm{C}$. The onset of 
degradation temperature was $385^{\circ} \mathrm{C}$ which is just above the value measured by other researchers [1,28] of approximately $380^{\circ} \mathrm{C}$. The degradation temperature which is defined as the peak temperature of DTG thermogram was at $430^{\circ} \mathrm{C}$.

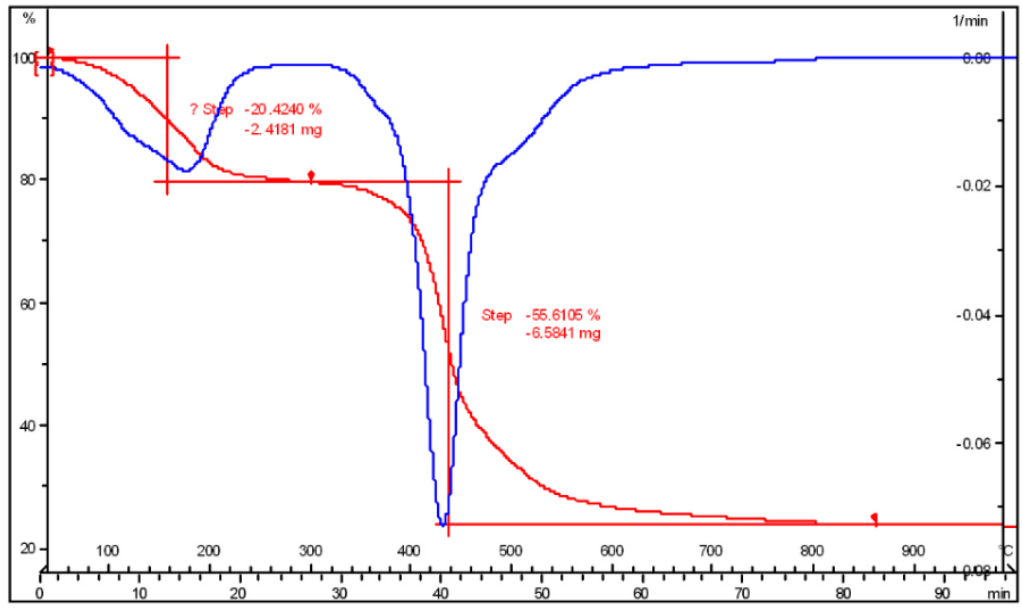

Fig. 13. Derivative Thermogravimetric Analysis (DTG) of uncured SU8-2100.

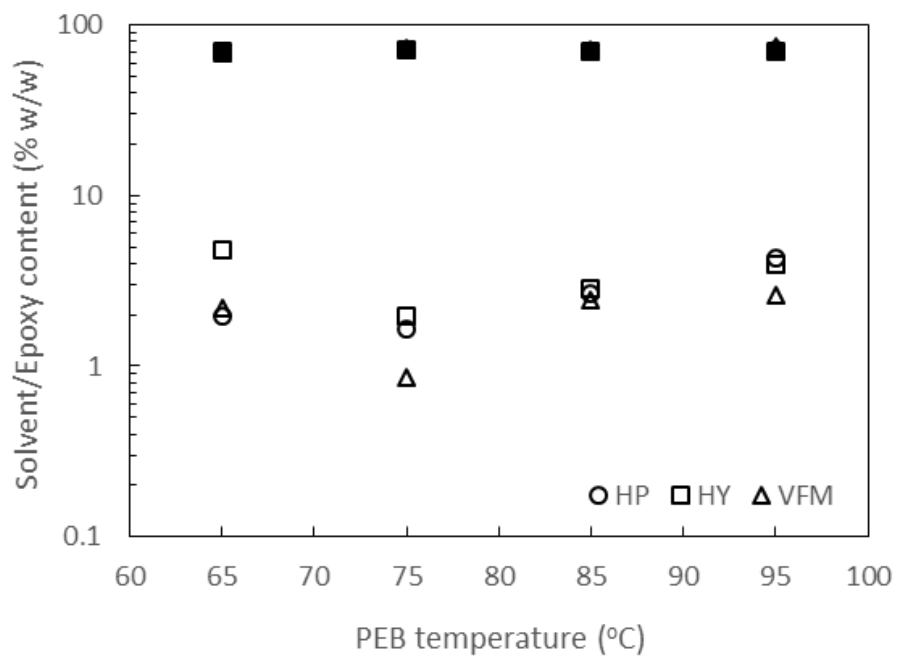

Fig. 14. Solvent and epoxy contents of the cured SU8-2100 (unfilled symbols: solvent content; filled symbols: epoxy content). 


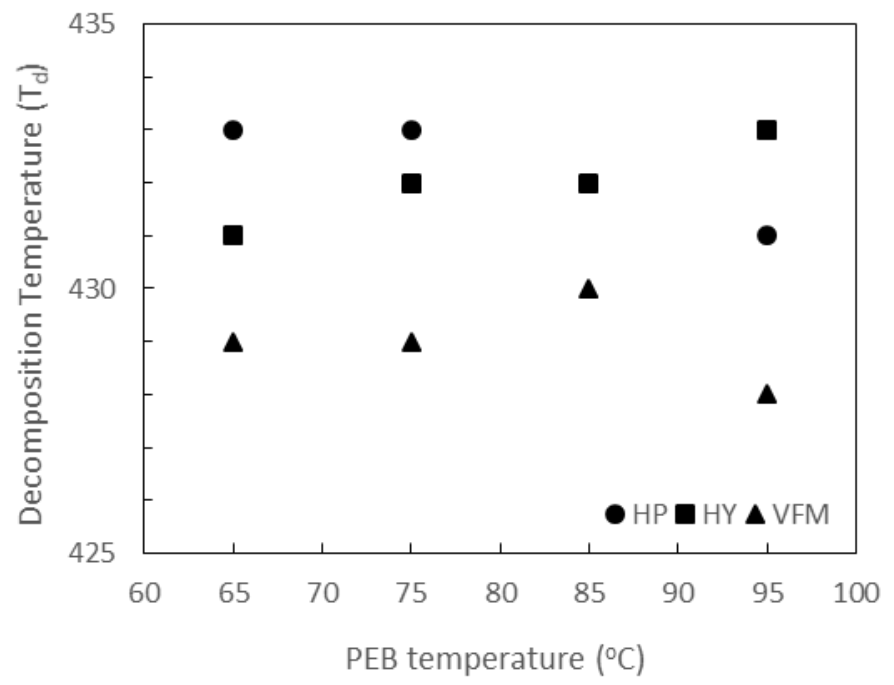

Fig. 15. Degradation temperatures of SU8 samples cured by different pathways and PEB temperatures.

As the SU8 was cured via different curing pathways, most of solvent have been evaporated and only $<5 \%$ content remained in the cured film as can be seen from Fig. 14. One would expect that greater solvent evaporation occurs as the curing temperature increased; however, the result showed no particular relationship between curing temperature and residual solvent or the relationship between curing pathway and residual solvent. Nevertheless, the results of epoxy content of the cured samples via different PEB temperatures and pathways were very similar, approximately $70 \% \mathrm{w} / \mathrm{w}$. The onset degradation temperatures were around $400^{\circ} \mathrm{C}$ for all cured samples which is slightly higher than that of uncured SU8, suggesting greater thermal stability. The degradation temperatures of both uncured and cured SU8 were fairly similar at $\sim 430^{\circ} \mathrm{C}$ independently of PEB temperatures and curing pathways as shown in Fig. 15.

\subsection{Morphology and Flatness of Cured Samples}

The curing of SU8 photoresist films leads to the fabrication of microstructures required in the MEMS industry. Different curing techniques can affect the quality of the microstructures obtained. These microstructures require good structural stability, good resolution (i.e. definition and sharpness of edges or corners) and adhesion. The results of the effects of curing pathways on the morphology of the films are discussed elsewhere [33]. However, a summary of the results are shown below as it will be linked to and supports other results in this study. Table 4 summarizes morphological results and problems that were encountered for different curing pathways. Optical studies of the microstructures fabricated suggest that films that have a degree of cure of $<60 \%$ resulted in poor quality microstructures. The VFM was found to achieve satisfactory microstructures at most of the temperatures used compared to only the high temperatures for the HP and HY pathways. At the highest temperature used $\left(95^{\circ} \mathrm{C}\right)$, and to some degree even at the lower processing temperatures, the microstructures that were developed were prone to microscopic cracking most probably due to the low solvent content and high degree of curing. These microcracks could be minimized by controlling the rate of heating and/or controlling the final solvent content in the microstructures.

Figure 16 shows the surface profiles of the substrate with cured SU8 samples at HP95 and VFM95. It is evident in the figure that significant bowing is occurring in both samples. During SB and PEB, the curing reaction is typically associated with significant shrinkage of the SU8 coating due to the molecular chains being pulled closer together by the crosslinks. Due to the large mismatch in coefficient of thermal expansion (CTE) between SU8 $(50 \mathrm{ppm} / \mathrm{K})$ and the silicon substrate $(2.33 \mathrm{ppm} / \mathrm{K})$, bowing of the substrate is a common occurrence and is more pronounced at higher curing temperatures. In the case of the HP curing method, as a result of the wafer bowing, the surface contact between the substrate and hotplate is compromised resulting in only partial contact or at worst, point contact with the hotplate surface therefore affecting the heat transfer to the sample and thus lowering the curing rate. On the other hand, the 
limitations of heat transfer are eliminated in the VFM as MW radiation is absorbed directly by both the substrate and the SU8 coating. Therefore bowing of the substrates will not have an effect on the heat transfer to or within the sample during VFM curing.

Table 4. Summary of microstructures of cured SU8 by different curing pathways.

\begin{tabular}{lll}
\hline Curing pathway & Problems/Comments & Quality \\
\hline HP65 & Poor resolution, swelling, tapering, semi-developed & unsatisfactory \\
HP85 & Poor resolution, swelling, tapering, semi-developed & unsatisfactory \\
HP95 & Tapering of edges & satisfactory \\
HY65 & Tapering of edges, cracks developing & satisfactory \\
HY75 & Poor resolution, swelling, tapering, semi-developed & unsatisfactory \\
HY85 & Slightly better resolution, swelling, tapering, small undeveloped & unsatisfactory \\
HY95 & areas, structure failure & \\
VFM65 & Slight tapering of edges & satisfactory \\
VFM75 & Very poor resolution, swelling, cracking, structure failure & satisfactory \\
VFM85 & Tapering, cracking & unsatisfactory \\
VFM95 & Swelling & satisfactory \\
\hline
\end{tabular}

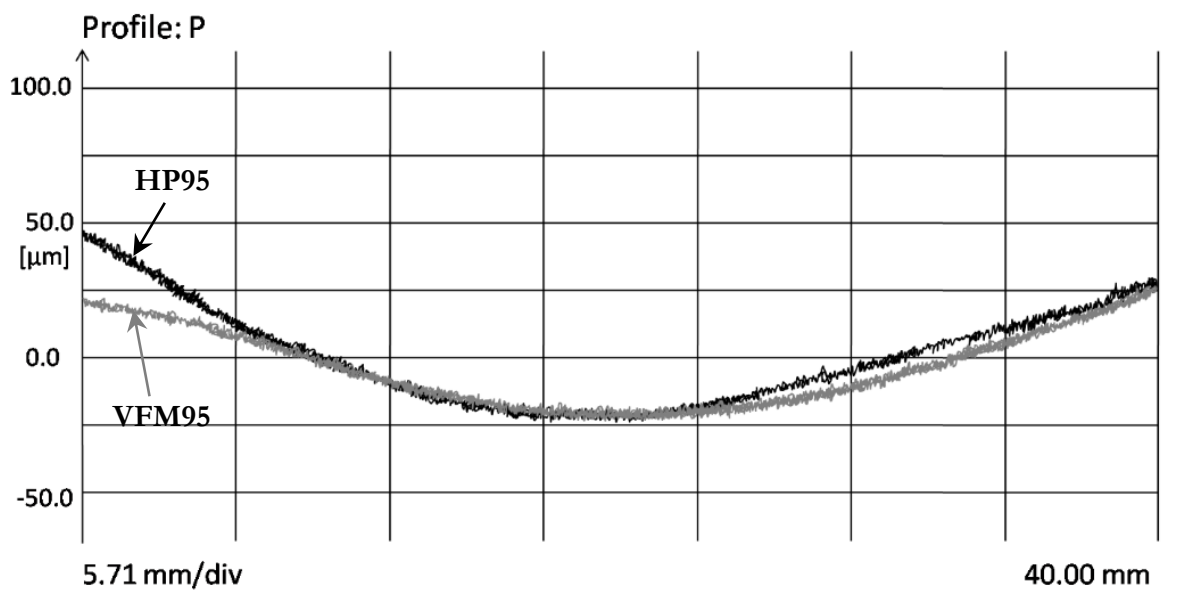

Fig. 16. Surface profile of cured SU8 samples under HP95 and VFM95.

\subsection{Curing of Thick Samples}

Table 5 shows a comparison between thermal properties of the thick ( $>500 \mu \mathrm{m})$ SU8-2100 films obtained from HP95 and VFM95. Substantially lower degrees of curing in comparison to those of the thin film for both techniques were observed and maybe because at the beginning of the SB there is a large difference in evaporation rate between the bulk (interior) and the surface of the film and as the solvent near the surface evaporates the surface densifies, and a 'skin' appears on the surface of the film. As the baking continues, 
the skin becomes thicker and evaporation of solvent from the interior halts. Thus resulting in a hard top layer but quite a soft inner layer which was observed when obtaining samples for thermal testing. Nevertheless, despite the low degree of cures obtained, the degree of cure was still found to be higher using the VFM and the solvent content lower as compared to the conventional hotplate processing as experienced with the thinner films.

Table 5. Thermal properties of thick SU8-2100 films cured by HP and VFM at PEB of $95^{\circ} \mathrm{C}$.

\begin{tabular}{lccc}
\hline Curing pathway & Degree of curing $(\%)$ & Solvent content $(\%)$ & Degradation temperature $\left({ }^{\circ} \mathrm{C}\right)$ \\
\hline HP95 & 48.5 & 7.5 & 405 \\
VFM95 & 56.2 & 6.3 & 403 \\
\hline
\end{tabular}

\section{Conclusions}

The Variable Frequency Microwave (VFM) technique is a new processing method which has the capabilities to overcome many of the obstacles that conventional fixed frequency microwave processing, such as non-uniform heating, has faced. This study has shown the feasibility of the VFM technique as an alternative method for the processing of negative tone SU8 photoresist in the MEMS industry. Dielectric studies of the samples suggested substrate heating as one of the main contributors to sample heating; however it is more likely that a combination of substrate heating and dielectric heating is the reason for the increase in cure rates. The increase in cure rates means that SU8 can be processed at lower temperatures thus alleviating internal stress due to the mismatch of CTE between the SU8 film and the Si substrate and/or decreasing cure times of an otherwise lengthy cure. A significant increase on the degree of cure was observed using the VFM over the hybrid and hotplate curing which means that SU8 curing at lower temperatures or rapid curing is possible. The increase in cure rates can be attributed to a combination of heat transfer and the unique capability of microwave to couple with the sample (selective heating). Thermal analysis of the cured samples suggested that there is very little difference in the thermal properties of the films cured. Optical studies of the microstructures fabricated suggest that films that have a degree of cure of $<60 \%$ resulted in poor quality microstructures. The VFM was found to achieve satisfactory microstructures at most of the temperatures tested compared to only the high temperatures for the hotplate and hybrid methods, although the microstructures were prone to microscopic cracking at the highest temperature used most probably due to the low solvent content and high degree of curing.

\section{References}

[1] N. LaBianca and J. Gelorme, "High aspect ratio resists for thick film applications," in Proc. SPIE 1995 Symposium on Microlithography, vol. 2438, pp. 846-852,.

[2] H. Lorenz, M. Despont, N. Fahrni, J. Brugger, P. Vettiger, and P. Renaud, "High-aspect-ratio, ultrathick, negative-tone near-UV photoresist and its applications for MEMS," Sensor. Actuat. A-Phys, vol. 64, pp. 33-39, 1998.

[3] A. L. Bogdanov and S. S. Peredkov, "Use of SU-8 photoresist for very high aspect ratio x-ray lithography," Microelectron. Eng., vol. 53, pp. 493-496, 2000.

[4] H. Lorenz, M. Laudon, and P. Renaud, "Mechanical characterization of a new high-aspect-ratio near UV-photoresist," Microelectron. Eng., vol. 41/42, pp. 371-374, 1998.

[5] J. P. Esquivel, T. Senn, P. Hernándex-Fernández, J. Santander, M. Lörgen, S. Rojas, B. Löchel, C. Cané, and N. Sabaté, "Towards a compact SU-8 micro-direct methanol fuel cell," J. Power Sources, vol. 195, pp. 8110-8115, 2010.

[6] K. Gut, "Bimodal layers of the polymer SU8 as refractometer," Procedia Eng., vol. 47, pp. 326-329, 2012.

[7] W. Jung, Y. W. Kim, D. Yim, and J. Y. Yoo, "Microscale surface thermometry using SU8/Rhodamine-B thin layer," Sensor. Actuat. A-Phys., vol. 171, pp. 228-232, 2011.

[8] N. Vasylieva, S. Marinesco, D. Barbier, and A. Sabac, "Silicon/SU8 multi-electrode micro-needle for in vivo neurochemical monitoring," Biosens. Bioelectron., vol. 72, pp. 148-155, 2015. 
[9] S. Marchesan, C. D. Easton, K. E. Styan, P. Leech, T. R, Gengenbach, J. S. Forsythe, and P. G. Hartley, "SU-8 photolithography on reactive plasma thin-films: coated microwells for peptide display," Colloid. Surface. B, vol. 108, pp. 313-321, 2013.

[10] S. Jiguet, A. Bertsch, M. Judelewicz, H. Hofmann, and P. Renaud, "SU-8 nanocomposite photoresist with low stress properties for microfabrication applications," Microelectron. Eng., vol. 83, pp. 1966-1970, 2006.

[11] C.-H. Ho, K.-P. Chin, C.-R. Yang, H.-M. Wu, and S.-L. Chen, "Ultrathick SU-8 mold formation and removal, and its application to the fabrication of LIGA-like micromotors with embedded roots," Sensor. Actuat. A, vol. 102, pp. 130-138, 2002.

[12] M. Sangermano, L. Calvara, E. Chiavazzo, L. Ventola, P. Asinari, V. Mittal, R. Rizzoli, L. Ortolani, and V. Morandi, "Enhancement of electrical and thermal conductivity of Su-8 photocrosslinked coatings containing graphene," Prog. Org. Coat., vol. 86, pp. 143-146, 2015.

[13] M. Majidian, C. Grimaldi, A. Pisoni, L. Forró, and A. Magrez, "Electrical conduction of photopatterable SU8-graphene composites," Carbon, vol. 80, pp. 364-372, 2014.

[14] H. C. Chiamori, J. W. Brown, E. V. Adhiprakasha, E. T. Hantsoo, J. B. Straalsund, N. A. Melosh, and B. L. Pruitt, "Suspension of nanoparticles in SU-8: Processing and characterization of nanocomposite polymers," Microelectron. J., vol. 39, pp. 228-236, 2008.

[15] S. Jiguet, M. Judelewicz, S. Mischler, H. Hofmann, A. Bertsch, and P. Renaud, "SU-8 nanocomposite coatings with improved tribological performance for MEMS," Surf. Coat. Tech., vol. 201, pp. 2289-2295, 2006.

[16] S. Keller, G. Blagoi, M. Lillemose, D. Haefliger, and A. Boisen, "Processing of thin SU-8 films," J. Micromech. Microeng., vol. 18, No. 12, pp. 125020, 2008.

[17] L. Amato, S. S. Keller, A. Heiskanen, M. Dimaki, J. Emnéus, A. Boisen, and M. Tenje, "Fabrication of high-aspect ratio SU-8 micropillar arrays," Microelectron. Eng., vol. 98, pp. 483-487, 2012.

[18] M. Kubenz, U. Ostrzinski, R. Reuther, and G. Gruetzner, "Effective baking of thick and ultra-thick photoresist layer by infrared radiation," Microelectron. Eng., vol. 67-68, pp. 495-501, 2003.

[19] G. Bleidiessel, G. Gruetzner, F. Reuther, S. Fehlberg, B. Loechel, and A. Maciossek, "Dependence of the quality of thick resist structures on resist baking," Microelectron. Eng., vol. 41/42, pp. 433-436, 1998.

[20] H. S. Ku and T. Yusaf, "Processing of composites using variable and fixed frequency microwave facilities," Prog. Electromagn. Res. B, vol. 5, pp. 185-205, 2008.

[21] P.-C. Sung, T.-H. Chiu, and S.-C. Chang, "Microwave curing of carbon nanotube/epoxy adhesives," Compos. Sci. Technol., vol. 104, pp. 97-103, 2014.

[22] K. D. Farnsworth, R. N. Manépalli, S. A. Bidstrup-Allen, and P. A. Kohl, "Variable frequency microwave curing of photosensitive polyimides," IEEE T. Compon. Pack. T., vol. 24, no. 3, pp. 474481, Sept. 2001.

[23] K. Johnston, S. K. Pavuluri, M. T. Leonard, M. P. Y. Desmulliez, and V. Arrighi, "Microwave and thermal curing of an epoxy resin for microelectronic applications," Thermochim. Acta, vol. 616, pp. 100$109,2015$.

[24] X. Xu, X. Wang, Q. Cai, X. Wang, R. Wei, and S. Du, "Improvement of the compressive strength of carbon fiber/epoxy composites via microwave curing," J. Mater. Sci. Technol, to be published. doi: 10.1016/j.jmst.2015.10.006

[25] M. Kwak, P. Robinson, A. Bismarck, and R. Wise, "Microwave curing of carbon-epoxy composites: Penetration depth and material characterization," Compos. Part A-Appl. S., vol. 75, pp. 18-27, 2015.

[26] U. L. de Vergara, M. Sarrionandia, K. Gondra, and J. Aurrekoetxea, "Polymerization and curing kinetics of furan resins under conventional and microwave heating," Thermochim. Acta, vol. 581, pp. 92-99, 2014.

[27] J. Jow, M. C. Hawley, M. Finzel, and T. Kern, "Dielectric analysis of epoxy/amine resins using microwave cavity technique," Polym. Eng. Sci., vol. 28, no. 22, pp. 1450-1454, 1988.

[28] R. Feng and R. Farris, "Influence of processing conditions on the thermal and mechanical properties of SU8 negative photoresist coatings," J. Micromech. Microeng., vol. 13, pp. 80-88, 2003.

[29] N. LaBianca, J. Gelorme, K. Lee, E. Cooper, E. O'Sullivan, and J. Shaw, "High aspect ratio optical resist chemistry for MEMs application," Electrochem. Soc. Proc., vol. 95, no. 18, pp. 386-396, 1993.

[30] S. K. Rath, F. Y. C. Boey, and M. J. M. Abadie, "Cationic electron-beam curing of a high-functionality epoxy: Effect of post-curing on glass transition and conversion," Polym. Int., vol. 53, pp. 857-862, 2004.

[31] L. E. Nielsen, "Cross-linking-effect on physical properties of polymers," J. Macromol. Sci. Pobym. Rev., vol. 3, pp. 69-103, 1969. 
[32] S. L. Simon and J. K. Gillham, "Cure kinetics of a liquid dicyanate ester monomer/high- $\mathrm{T}_{\mathrm{g}}$ polycyanurate material,” J. Appl. Polym. Sci., vol. 47, pp. 461-485, 1993.

[33] C. Antonio and P. Wattanachai, "Variable frequency microwave curing of SU8 photoresist films," Adv. Mat. Res., vol. 931-932, pp. 101-105, 2014. 